\title{
Pyogenic abscess of the liver
}

\author{
K. CRONIN
}

From the Division of Surgery, The Radcliffe Infirmary, Oxford

SYNOPSIS The author records the case histories of 27 patients suffering from liver abscess admitted during the period 1946-60 to the Radcliffe Infirmary, Oxford. Seventeen were examples of multiple and 10 of single abscess. In most cases the primary source was determinable. Despite there being only one survivor of the 10 patients with a solitary abscess, the author considers the condition easily curable if recognized early.

In 1836, John Bright, physician to Guy's Hospital in London, published an account of eight patients with jaundice. Two died after short illnesses marked by rigors and jaundice, and the necropsy in each revealed multiple abscesses throughout the liver. Apart from emphasizing that neither patient had stones in the common bile duct, Bright did not speculate as to the cause of the abscesses. In retrospect, however, it seems reasonable to say that both patients had portal pyaemia, and although unrecognized as such they are the earliest description of the condition found by the present writer.

Ten years later, in 1846, Waller described a patient who died of acute appendicitis and at the necropsy was found to have had multiple abscesses of the liver with a purulent thrombophlebitis of the portal vein and its tributaries. Waller deduced correctly that the suppuration of the liver was a direct result of the inflamed appendix and to him must go the credit for recognizing portal pyaemia as a clinical entity.

By the turn of the century it was well known as a complication of appendicitis by the French (Achard, 1894; Feltz, 1895; Dieulafoy, 1898). In England, Guy's physicians and surgeons seem to have been particularly interested in the condition. Carrington (1883) reported nine cases, Bryant (1897) a further 11, and Taylor (1902) gave an excellent account of the clinical symptoms and signs with the pitfalls of diagnosis.

At the present time pyogenic abscess of the liver is an unusual disease and it is rare for any one clinician to see a large number of patients. The textbook triad of swinging temperature, rigors, and jaundice is more the exception than the rule so that the clinical picture is often confusing, the diagnosis difficult, and the treatment uncertain.

In this paper 27 patients with pyogenic abscess of the liver are considered. They were admitted to the
Radcliffe Infirmary between 1946 and 1960. This 15-year span has been particularly chosen because at its beginning antibiotics first appeared and have been used increasingly ever since. Nine patients have been excluded in whom abscesses were due to ascending cholangitis from obstruction of the common bile duct and three where the abscesses were part of a general septicaemia. This has been done because neither of these two groups really falls within the province of the main argument.

\section{SEX AND AGE INCIDENCE}

There were 18 men $(68 \%)$ and nine women $(32 \%)$, and the average age of the 27 patients was 61 years. More relevant than these bare figures is the fact that nine of these 27 patients were in their 70 s or 80 s. It is, therefore, important to realize that nowadays liver abscesses are often an affliction of the old and feeble. In the past the average age has been considerably lower (Bryant, 1897; Rothenberg and Linder, 1934; Ochsner, DeBakey, and Murray, 1938) because such series had a predominance of cases of appendicitis which weighted the figures in favour of youth.

\section{TYPE OF ABSCESS}

Seventeen $(64 \%)$ of the patients had multiple abscesses and $10(36 \%)$ a single one. The right lobe was affected in 12 patients, the left in two, and both lobes in seven. Two patients died with multiple abscesses and two with large solitary ones, but the necropsy report is not clear about which part of the liver was affected. Two patients with appendicitis and the symptoms and signs of liver involvement recovered on antibiotics alone so that it is impossible to be sure of the situation of the abscesses. 
CAUSE OF THE ABSCESS

The source of the primary infection is shown in Table I.

TABLE I

SOURCE OF PRIMARY INFECTION

No. of Diagnosis

\begin{tabular}{|c|c|c|}
\hline & $\begin{array}{l}\text { No. of } \\
\text { Cases }\end{array}$ & Diagnosis \\
\hline $\begin{array}{l}\text { Group I } \\
\text { Infiammation, } \\
\text { ulceration, or } \\
\text { perforation of } \\
\text { the bowel }\end{array}$ & $9(35.7 \%)$ & 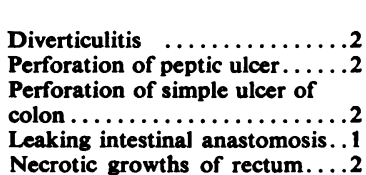 \\
\hline
\end{tabular}

Group II

Acute appendicitis $5(21 \cdot 3 \%)$

Group III

Acute cholecystitis $2(7 \cdot 1 \%)$

Group IV

Miscellaneous $\quad 3(14.2 \%)$

Total gastrectomy .........1

Multiple pancreatic abscesses.... Abscess of femoral hernial sac...1

Group $V$

No cause found $8(21.4 \%)$

Amongst the early writers on portal pyaemia, acute appendicitis was by far the commonest cause. Bryant (1897) said that it was responsible in eight $(40 \%)$ of the 20 patients recorded by himself and Carrington (1883) and Langdon Brown (1901) in a collected series of 64 cases found that $27(43 \%)$ had appendicitis. The complication being considered something of an oddity, sporadic case reports continued to appear and by 1926 Eliason was able to find 53 scattered in the literature.

At present, appendicitis no longer plays such a large part in the aetiology of liver abscesses. Ochsner et al. (1938) found that it only accounted for $10.6 \%$ of their personal cases and Bourne (1954) quotes a figure of $18 \%$; in the present series of 27 patients there were five with appendicitis, an incidence of $18 \%$. In so far as there is no case selection at the Radcliffe Infirmary and no 'emergency' is ever refused admission, it is fair to say that nowadays in just under a fifth of patients with liver abscesses, appendicitis is the cause. Over the same 15-year period, 8,638 patients were admitted with acute appendicitis so that portal pyaemia occurred as a complication in $0.05 \%$.

The most interesting group are the eight patients who had no obvious primary focus of infection. Traditionally, such abscesses have been given the rather ungainly title of 'cryptogenic'.

There is little doubt that the single liver abscess is much more likely to appear de novo than the multiple. In the present series six out of 10 single abscesses had no obvious cause whereas this only happened twice in the 17 patients with multiple abscesses. This is confirmed by other writers. Rothenberg and Linder (1934) reported that 19 out of 24 solitary abscesses were cryptogenic and McFadzean, Chang, and Wong (1953) found the same in 12 of their 14 patients. Bourne (1954) says that twice as many cryptogenic abscesses are single as multiple.

Even accepting the fact that there is no obvious source of infection within the portal area, it is still plain that the abscess is not a primary event. Lepehne (1929) has argued that dissemination of septic emboli by the hepatic artery may account for some cases of multiple abscesses and Rothenberg and Linder (1934) have taken much the same view with the single abscess. These last two authors compare the solitary liver abscess to osteomyelitis or a carbuncle of the kidney and in support of their views claim that nine of their 24 patients had evidence of focal infection.

Beaver (1931) denied that infection could reach the liver by the hepatic artery except in the course of a generalized septicaemia. He went on to maintain that in all liver abscesses, single or multiple, there must be a primary focus somewhere within the portal area. This may be relatively so slight in character that its presence is overshadowed by the secondary abscess in the liver.

It is impossible to decide definitely between these two theories although the second would seem to be the more plausible of the two. Nevertheless, in fairness it has to be admitted that in the six fatal cases of cryptogenic abscess in this series a careful necropsy failed to reveal any source of infection within the abdomen or elsewhere in the body. Of the two patients with no cause for multiple abscesses one recovered (Case 1) and the other died (Case 2). At necropsy in this second patient there was pus in all the veins draining the sigmoid colon but the bowel itself seemed normal. These findings would seem to lend support to Beaver, as it is hard to believe that the infection could have come from anywhere but the gut.

\section{DIAGNOSIS}

'The chief aid to the diagnosis of the disease is the knowledge that it may occur' (Taylor, 1902). Although it is impossible to say that any one symptom or sign occurs in every case, some appear sufficiently often that when considered together they form a reasonably coherent clinical picture. The chief symptoms and signs are shown in Fig. 1, and the incidence compared with the personal series of 47 cases of Ochsner et al. (1938). 


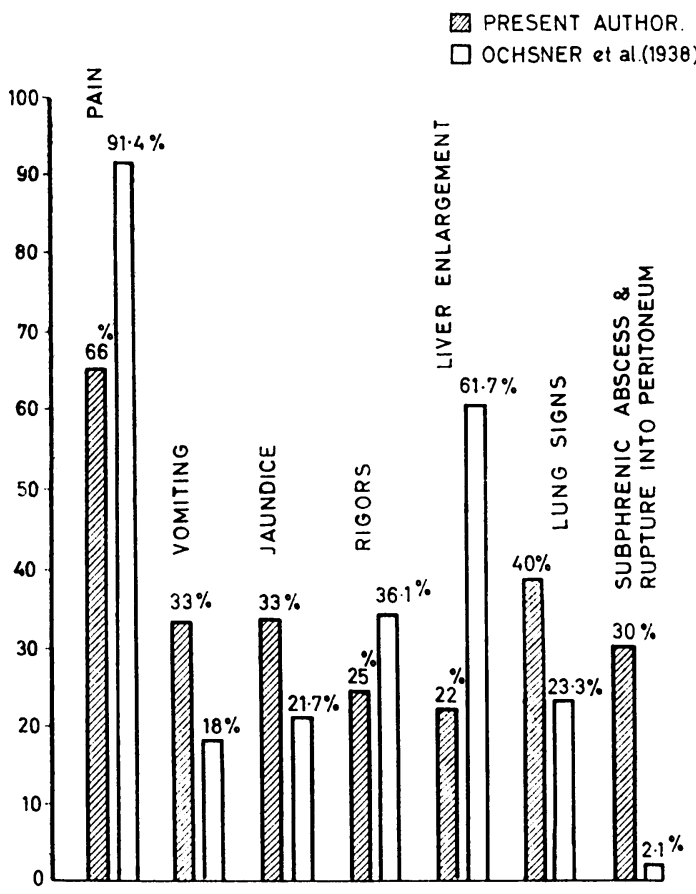

FIG. 1. Diagram of signs and symptoms in present series compared with those found in the series of Ochsner et al. (1938).

PAIN AND vomiting Pain in the epigastrium and under the right costal margin was the most constant symptom, being present in two-thirds of the patients. In contrast vomiting is unusual and was absent in nearly two-thirds. The divorce between these two common symptoms is peculiar to liver abscesses and helps in distinguishing them from most other upper abdominal conditions in which pain and vomiting usually go hand in hand.

JAUNDICE Jaundice is usually considered a sine qua non of diagnosis but in fact it was only found in a third of the patients. It was present in about half those with multiple abscesses but in only one of the 10 with a single abscess. Jaundice seems particularly liable to appear when the appendix is at fault. All five patients with appendicitis in the present series were jaundiced, and Eliason (1926) says that it is invariably present when the abscess, whether single or multiple, complicates appendicitis. As this condition no longer monopolizes the aetiology, jaundice has become rarer.

In two patients of the present series, however, it was the only evidence of liver involvement. As the two histories are virtually identical only one is given (Case 3).
It might be argued that infection of the liver was not the cause of the jaundice but it is difficult to see how else it could be explained. Presumably the antibiotics in each patient successfully aborted the attack before extensive suppuration had taken place.

TEMPERATURE AND RIGORS Nearly all the patients had some degree of pyrexia but only a quarter the traditional 'swinging' septic chart, which was twice as common in those with multiple abscesses. The majority merely confirmed Bryant's point, made in 1897 , that any type of temperature can occur.

As might be expected from this, rigors were exceptional and were only recorded in a quarter of the patients, of whom the overwhelming majority had multiple abscesses.

ENLARGEMENT OF THE LIVER Although a palpable tender liver is mentioned by most writers, it was found in less than a quarter of the present series. This figure is probably too low, because Ochsner et al. (1938) found enlargement in nearly two-thirds of their cases and both Rothenberg and Linder (1934) and McFadzean et al. (1953) say that the liver could be felt in nearly all their patients with a solitary abscess. It should be remembered, however, that as the increase in size is sometimes upwards, it may only be detected on a radiograph showing elevation of the right diaphragm.

Eliason (1926) mentions oedema and tenderness of the tissues over the right lower ribs as two valuable and constant signs but neither was detected in any of the patients in this series. This may be an error of clinical omission rather than commission.

SIGNS AT THE BASE OF THE RIGHT LUNG John Bright in the account of his second patient mentions that there was dullness at the base of the right lung. Most writers since then have made the same observation, which, if correctly interpreted, may be of considerable diagnostic value. It may equally prove a snare by distracting the attention of the clinician from the abdomen to the chest. Eliason (1926), in 53 cases of liver abscess collected from the literature, found that the initial clinical diagnosis in most had been a right basal pneumonia.

As the lung infection is in part due to the enlarged liver pressing upwards and causing a basal collapse, it is more commonly present with the single abscess. In the present series half of the patients with a solitary abscess had lung signs whereas these were only found in a third of the multiple abscess cases.

SUBPHRENIC ABSCESS AND RUPTURE INTO THE PEROTONEUM If the abscess continues to grow it may finally burst into one of the subphrenic spaces or 
else into the general peritoneal cavity. This happened in just under a third of the present patients, five developing subphrenic abscesses and three dying of general peritonitis. Both single and multiple abscesses seem equally liable to these complications.

The development of a subphrenic abscess (Case 4) may further confuse the diagnosis by masking the underlying liver infection. Granger (1930) has drawn attention to radiological differences in the chest films which may help in distinguishing between a 'simple subphrenic' and one secondary to a liver abscess. In the former the costophrenic angle is obliterated in the postero-anterior view of the chest and the posterior costophrenic angle on the lateral view. On the other hand, where there are both liver and subphrenic abscesses present, it is the cardiophrenic angle (instead of the costophrenic) which disappears on the postero-anterior view and the anterior (not the posterior) costophrenic angle is absent on the lateral view.

\section{RADIOLOGY}

Radiography may also help in the diagnosis of a liver abscess in one of three ways: (1) by showing elevation and fixation of the right half of the diaphragm together with changes in the overlying lung field (Pancoast, 1926); (2) an abscess of the right lobe may produce distortion of the right renal pyelogram (Yates, 1953); (3) an abscess in the left lobe may deform the lesser curve of the stomach in barium meal examination (Miles, 1936).

\section{LABORATORY INVESTIGATIONS}

The white cell count tended as a rule to be raised, being higher in the patient with multiple than single abscess. There were, however, many inconsistencies between the condition of the liver and the degree of leucocytosis, comparatively low counts sometimes going with extensive suppuration.

One valuable investigation is the estimation of the serum alkaline phosphatase. Hirschowitz (1952) says that if this is raised and all the other liver function tests are normal, it is strongly suggestive of either an abscess or a growth within the liver.

\section{DISCUSSION}

In the late nineteenth century physicians were only reluctantly allowing typhilitis to fade into a historical limbo and appendicitis to replace it on the surgical scene. The result was that many patients died of advanced peritonitis with their livers riddled with abscesses. The clinical picture of these unfortunates, drawn by the English and French writers of that time, has now become part of surgical lore. Case 5 could equally find a place in the modern textbook or the late Victorian surgical journal. Yet of the 17 patients with multiple abscesses in the present series it was only the five with appendicitis who in any way conformed to this classical pattern. The rest were exceptions to the rule.

Two patients (Cases 6 and 7) with diverticulitis and multiple abscesses had no clinical evidence of colonic inflammation so that their rigors and jaundice were misinterpreted as due to stones in the common bile duct. Four similar cases with a 'silent' diverticulitis causing liver abscesses were reported by Shaldon (1958). A third patient (Case 1) had such severe upper abdominal pain that he was diagnosed as a perforated peptic ulcer. In these three patients a primary focus of infection was either inconspicuous or absent so that the liver abscesses were misdiagnosed as two more common upper abdominal conditions. In two of the three (Cases 1 and 7) the correct diagnosis was made at laparotomy and at necropsy in the third (Case 6).

Amongst a further seven patients, four had general peritonitis, two late necrotic rectal growths, and the last a pancreas full of abscesses. Some were moribund on admission and all were dead within 48 hours. In this group the liver abscesses were silent in so far as any local symptoms or signs were swamped by the severity of the primary lesion. Diagnosis if not impossible was certainly academic.

The last two patients do not fit into any welldefined group. One (Case 4) has already been discussed. The other developed what was thought to be a subphrenic abscess after a total gastrectomy. He soon died and the necropsy showed extensive suppuration throughout the portal tracts. The source of the infection was probably the duodenal stump. This patient was never jaundiced and it was this that mislead the clinicians. It is therefore worth reemphasizing that jaundice is rare in liver abscesses (other than those which complicate appendicitis) and in fact was only found in three of the 11 patients who died with multiple abscesses.

On the whole the solitary abscess is less fickle in its clinical presentation than the multiple. Yet in three patients of the present series the diagnosis was well nigh impossible. Two of the three were admitted and died in diabetic coma and the third had a general peritonitis from rupture of the abscess. A fourth patient had a laparotomy, when the abscess was found and successfully drained. In the remaining six the abscess was unsuspected and therefore undiagnosed until necropsy. Stokes (1960) has suggested that persistent upper abdominal pain with an unexplained fever should be sufficient to arouse suspicion of a solitary abscess. This may be true 
but the most important single step in diagnosis is to remember that the condition exists. If this is done the answer to the clinical riddle is not difficult.

\section{TREATMENT}

The mortality figures for the series are shown in Table II.

TABLE II

MORTALITY IN THE SERIES

\begin{tabular}{lccc} 
& $\begin{array}{l}\text { Number } \\
\text { of Patients }\end{array}$ & Survivors & $\begin{array}{l}\text { Mortality } \\
(\%)\end{array}$ \\
\hline Multiple abscesses & 17 & 6 & 66 \\
Solitary abscesses & 10 & 1 & 90 \\
Whole series & 27 & 7 & 75
\end{tabular}

Pyogenic abscess of the liver has always been considered a peculiarly lethal affliction. Dieulafoy (1898) believed that death was inevitable and he emphasized that this high mortality was one of the prices to be paid for failing to diagnose acute appendicitis. This fatalistic view was confirmed by the $100 \%$ mortality of the Guy's Hospital series (Carrington, 1883; Bryant, 1897). It is true that even in these early days there was the occasional survivor after drainage of the abscess (Treves, 1894; Morton, 1897; Loisson, 1900), but these were isolated triumphs.

Forty years later the prospect had only improved slightly. Ochsner et al. (1938) found a mortality of $72 \cdot 3 \%$ in their personal series and $79.6 \%$ in a collected series. Without operation, there was a $100 \%$ mortality in both groups. As can be seen from these figures in surgical drainage lay the only hope of survival. This met with some success in the case of the single abscess but all too often the multiple abscesses are so widely and deeply scattered that it is ineffective.

The appearance of antibiotics has considerably improved although not entirely transformed the outlook. Shaldon (1958) has insisted that antibiotics in themselves are not enough but must always be combined with drainage. The present writer feels that this is too sweeping a statement, because four of the five patients in this series in whom the liver infection followed on appendicitis recovered on antibiotics alone. The fifth was explored and a small collection of pus found over the right lobe of the liver which was softened over an area of $8 \mathrm{~cm}$. in diameter. A drain was put down to this point but it is dubious whether it played much part in the patient's recovery. The sixth and last survivor (Case 1) in the multiple abscess group did have his abscesses drained.
Corry (1960) believes that in severe cases the antibiotics must be given intensively and continuously over a long period if the liver infection is finally to be brought under control. The truth of this teaching is borne out by the fact that in three of the patients of the present series the chemotherapy had to be prolonged for two months before recovery was finally assured. The necessity for this lengthy treatment was not realized in one patient (Case 7) who eventually died. The present writer played a considerable part in the treatment of this man and in retrospect I feel that we gave too little chemotherapy for too short a time. The result was that as soon as he left hospital the infection within the liver became active again and he died.

The solitary abscess has always provided a more hopeful prognosis than the multiple. Twenty-five years ago, Rothenberg and Linder (1934) had 14 survivors amongst 24 patients. In more recent years McFadzean et al. (1953) successfully treated 14 patients by simple, closed aspiration and antibiotics, and Stokes (1960) reported three patients who recovered after open drainage and systemic antibiotics. The one survivor of the 10 patients with a solitary abscess in the present series also recovered after the pus was drained.

An early diagnosis is the heart of the matter in the treatment of liver abscesses. Yet, it must be admitted that of the 11 patients who died with multiple abscesses, seven had such extensive intraabdominal suppuration that death was almost certain. The mortality in this condition will probably always be high because the primary focus is so often lethal in its own right. This does not apply to the solitary abscess and it was a failure of diagnosis in the present series that was responsible for the mortality of $90 \%$. This failure in turn was due to the fact that a solitary liver abscess was never considered as a possibility so that many of these patients died by default with an easily curable condition.

\section{CASE REPORTS}

CASE 1 F.D. (R.I.253392), a man aged 54 years, was admitted on 11 March 1958 with acute upper abdominal pain. He had a rigid upper abdomen, and clinically was diagnosed as a perforated peptic ulcer. At operation, there was a multiloculated abscess $5 \mathrm{~cm}$. in diameter in the right lobe of the liver and a similar but slightly smaller one in the left lobe. There was no obvious primary focus of infection. The abscesses were drained and a course of terramycin was given post-operatively. The patient made an uneventful recovery, and left hospital a fortnight after his admission. A swab of the pus grew B.coli.

CASE 2 B.H. (R.I.100395/49), a man aged 31 years, was admitted on 9 January 1949 with what was thought to 
be acute appendicitis. At operation, however, a normal appendix was removed. He left hospital but continued to complain of vague abdominal pain for which no cause could be found. About a week before his death he was admitted to the local cottage hospital where he was found to have a distended, tender abdomen. His condition steadily deteriorated and he died on 11 April 1949. At necropsy the peritoneal cavity contained $2 \frac{1}{2}$ litres of pus which came from a ruptured abscess $10 \mathrm{~cm}$. in diameter in the left lobe of the liver, which also contained more abscesses. All the veins draining the sigmoid colon were full of pus which spread up into the splenic and portal veins as well. Although the pelvic colon was thickened it contained no lesion to account for the pylephlebitis.

CASE 3 W.S. (R.I.232136), a man aged 73 years, was admitted on 4 January 1960 with acute appendicitis. At operation a perforated gangrenous appendix was found and removed.

Postoperatively he started a course of terramycin but on the second day became jaundiced with tenderness in the right hypochondrium although the liver was not palpable. He had no rigors and only ran a low-grade fever. Penicillin was added to the terramycin and over the course of a week the jaundice slowly faded. The antibiotics were stopped on the eleventh post-operative day and the patient left hospital two weeks after the first appearance of the jaundice.

CASE 4 S.L. (R.I.55785/46), a man aged 72 years, was admitted on 4 April 1946 with the symptoms and signs of a perforated peptic ulcer. A straight radiograph of the abdomen showed a large amount of free air under the right diaphragm. He was treated conservatively with gastric suction, intravenous fluids, and a course of sulphadiazine. His course was stormy and by 26 April it was clear that he had a right subphrenic abscess. This was drained through the bed of the eleventh rib but the patient died 10 days later.

At necropsy there were multiple abscesses in the right lobe of the liver, one of which had ruptured through the bare area to form the subphrenic collection.

CASE 5 M.S. (R.I.265974), a man aged 17 years, was admitted on 9 December 1958 with a history of 14 days' abdominal pain, seven days' rigors, and five days' jaundice. A clinical diagnosis of a general peritonitis from a perforated appendix and portal pyaemia was confirmed at operation. The liver was enlarged and reddish-purple but had no obvious abscesses on its surface. Over the next two months he was given courses of penicillin and streptomycin, penicillin and sulphadiazine, terramycin and aureomycin, one following the other without pause. The jaundice rapidly faded but he continued to run a swinging temperature with rigors for many weeks. He finally left hospital, symptom free, nine weeks after his admission.

CASE 6 J.R. (R.I.119499), a man aged 69 years, was admitted on 5 February 1950. For five days he had been having right-sided abdominal pain with rigors and he became jaundiced shortly after entering hospital. He was thought to have stones in the common bile duct but in spite of a course of penicillin and sulphadiazine, the jaundice steadily deepened. His condition was too poor to permit a laparotomy and he finally died on 23 February. At the necropsy there were multiple abscesses in the right lobe of the liver and an acute diverticulitis of the sigmoid colon.

CASE 7 S.G. (R.I.233487), a man aged 59 years, was admitted on 10 December 1956 with a history of a fortnight's rigors and jaundice. He was clinically thought to have stones in the common bile duct. At laparotomy, however, he was found to have an acute diverticulitis of the sigmoid colon and the liver was enlarged and friable although there were no obvious abscesses. He was started on a course of antibiotics, and a month after the operation the right lobe of the liver was needled and pus aspirated which grew B.coli on culture. The antibiotics were continued and his clinical condition improved, the rigors ceased, and his temperature returned to normal. He left hospital eight weeks after the operation but relapsed at home and died three weeks later. No necropsy was done.

\section{SUMMARY}

Twenty-seven patients with pyogenic abscesses of the liver are reviewed. Seventeen patients had multiple abscesses and 10 a solitary abscess. A third of the patients were in their seventh or eighth decade.

Multiple abscesses usually have an obvious cause but six out of 10 solitary abscesses were cryptogenic. Appendicitis at present accounts for about a fifth of the cases of portal pyaemia.

Upper abdominal pain is the commonest symptom. Jaundice occurred in only a third of the patients and rigors in a quarter.

Antibiotics can be very valuable in treatment but in severe cases they must be given intensively and for a prolonged period. Drainage is not always necessary.

There was a mortality of $66 \%$ in the multiple abscess group and $90 \%$ in those with a solitary abscess. The single abscess is easily curable if diagnosed and it was failure of diagnosis that was responsible for the high mortality in this group.

I should like to thank consultants of the Radcliffe Infirmary for allowing me to publish the details of patients admitted under their care. I am very grateful to $\mathrm{Mr}$. D. C. Corry and Mr. A. S. Till for their help and advice in the preparation of this paper.

\section{REFERENCES}

Achard, C. (1894). Infection due foie compliquant l'appendicite; pathogénie des abcès aréolaires. Bull. Soc. méd. Hôp. Paris, 11, (3rd ser.), 793-805. 
Beaver, D. C. (1931). Granulomatous abscess of the liver of pyogenic origin. Amer. J. Path., 7, 259-276.

Bourne, W. A. (1954). The diagnosis of pyogenic abscess of the liver. Lancet, 2, 1093-1094.

Bright, J. (1836). Observations on Jaundice; more particularly on that form of the disease which accompanies the diffused inflammation of the substance of the liver. Guy's Hosp. Rep., 1, 630-637.

Brown, W. L. (1901). Suppurative Pylephlebitis. St Bart's Hosp. Rep., 37, 95-135.

Bryant, J. H. (1897). Suppurative Pylephlebitis. Guy's Hosp. Rep., 54, $77-112$.

Carrington, R. E. (1883). Cases of multiple small abscess of the liver. Ibid, 26, 374-438 (n.s. 4).

Corry, D. C. (1960). Personal communication.

Dieulafoy (1898). La foie appendiculaire; abcès du foie consécutifs à l'appendicite. Sem. méd. (Paris), 18, 449-452.

Eliason, E. L. (1926). Pylephlebitis and liver abscess following appendicitis. Surg. Gynec, Obstet, 42, 510-522.

Feltz (1895). Appendicite compliqueé d'abcès aréolaire du foie. Bull. Soc. méd. Hóp. Paris, 12 (3rd series), 321-326.

Granger, A (1930). Radiological signs of subdiaphragmatic abscess. New Orleans med. surg. J., 82, 748-751.

Hirschowitz, B. I. (1952). Pyogenic liver abscess; review with case report of solitary abscess caused by Salmonella enteritidis. Gastroenterology, 21, 291-299.

Lepehne, G. (1929). Die Erkranbugen der Leber und Gallenwege der Leberabszess. Münch. med. Wschr., 76, 849-851.
Loisson, E. (1900). Des Suppurations intra et péri-hépatiques d'origine typhlo-appendiculaire. Rev. Chir., 21, 522-539.

McFadzean, A. J. S., Chang, W. P. S., and Wong, C. C. (1953). Solitary pyogenic abscess of liver treated by closed aspiration and antibiotics; report of 14 consecutive cases with recovery. Brit. J. Surg., 41, 141-152.

Miles, J. M. (1936). Roentgenological diagnosis of abscess on concave surface of liver. Amer. J. Roentgenol., 35, 65-69.

Morton, C. A. (1897). Bristol med.-chir. J., 15, 323-324.

Ochsner, A., DeBakey, M., and Murray, S. (1938). Pyogenic abscess of liver; analysis of 47 cases with review of literature. Amer. J. Surg., 40, 292-319.

Pancoast, H. K. (1926). Roentgenological diagnosis of liver abscess with or without subdiaphragmatic abscess. Amer. J. Roentgenol., 16, 303-320.

Rothenberg, R. E., and Linder, W. (1934). Single pyogenic liver abscess; study of 24 cases. Surg. Gynec. Obstet., 59, 31-40.

Shaldon, C. (1958). Portal pyaemia. Brit. J. Surg., 45, 375-360.

Stokes, J. F. (1960). Cryptogenic liver abscess. Lancet, 1, 355358.

Taylor, F. (1902). A case of suppurative pylephlebitis. Guy's Hosp. Rep., 56, 109-126.

Treves, F. (1894). A case of suppurative pylephlebitis in which laparotomy was performed. Lancet, 1, 663-665.

Waller (1846). Quoted by Loisson.

Yates, T. M. (1953). Distortion of pyelogram by extrarenal lesion: liver abscess distortion of pyelogram. J. Urol. (Baltimore), 69, 309-314. 